by which isolates could be scored as mutator or non-mutator with $>95 \%$ confidence.

Complementation tests. Strains were transformed with plasmids carrying wild-type alleles for $m u t H$ (plasmid pGW1899) ${ }^{23}$, mutL (pGW1842) ${ }^{23}$, mutS $(\mathrm{pgW} 1811)^{23}, u v r D(\mathrm{pGT} 26)^{24}$, mutT $(\mathrm{pSK} 25)^{25}, d_{n a Q}(\mathrm{pMM} 5)^{26}$ and $d n a E$ $(\mathrm{pMK} 9)^{27}$, according to a standard protocol ${ }^{28}$. Fluctuation tests were conducted as described above, except that all strains were propagated in LB medium (containing $60 \mu \mathrm{g} \mathrm{ml}^{-1}$ of ampicillin where the strain was plasmid bearing), and five parallel cultures were used per fluctuation test.

Analysis of fluctuation test data. A local computer program using a LuriaDelbrück distribution-generating algorithm ${ }^{29}$ was used to calculate maximumlikelihood mutation rates from fluctuation test data. Approximate 95\% confidence intervals for the mutation rates illustrated in Fig. 1 were calculated from formulae $\mathrm{e}^{30}$. Approximate $95 \%$ confidence limits for the mutation rates illustrated in Fig. 3 are based on the theoretical variance of the maximumlikelihood estimate of $\ln (m)$, assuming normality, where $m$ is the expected number of mutations per culture.

Received 3 March; accepted 6 May 1997.

1. Drake, J. W. Spontaneous mutation. Annu. Rev. Genet. 25, 125-146 (1991).

2. Leigh, E. G. Natural selection and mutability. Am. Nat. 104, 301-305 (1970).

3. Ishii, K., Matsuda, H., Iwasa, Y. \& Sasaki, A. Evolutionarily stable mutation rate in a periodically changing environment. Genetics 121, 163-174 (1989).

4. Taddei, F. et al. Role of mutator alleles in adaptive evolution. Nature 387 700-702 (1997).

5. Cox, E. C. \& Gibson, T. C. Selection for high mutation rates in chemostats. Genetics 77, 169-184 (1974).

6. Chao, L. \& Cox, E. C. Competition between high and low mutating strains of Escherichia coli. Evolution 37, 125-134 (1983).

Tröbner, W. \& Piechocki, R. Competition between isogenic $m u t S$ and $m u t^{+}$populations of Escherichia coli K12 in continuously growing cultures. Mol. Gen. Genet. 198, 175-176 (1984).

8. Mao, E. F., Lane, L., Lee, J. \& Miller, J. H. Proliferation of mutators in a cell population. J. Bacteriol. 179, 417-422 (1997)

9. LeClerc, J. E., Li, B., Payne, W. L. \& Cebula, T. High mutation frequencies among Escherichia coli and Salmonella pathogens. Science 274, 1208-1211 (1996).

10. Modrich, P. Mismatch repair, genetic stability and tumour avoidance. Phil. Trans. R. Soc. Lond. B 347, 89-95 (1995).

11. Lenski, R. E., Rose, M. R., Simpson, S. C. \& Tadler, S. C. Long-term experimental evolution in Escherichia coli. I. Adaptation and divergence during 2,000 generations. Am. Nat. 138, 1315-1341 (1991).

12. Lenski, R. E. \& Travisano, M. Dynamics of adaptation and diversification: A 10,000-generation experiment with bacterial populations. Proc. Natl Acad. Sci. USA 91, 6808-6814 (1994).

13. Vasi, F., Travisano, M. \& Lenski, R. E. Long-term experimental evolution in Escherichia coli. II. Changes in life-history traits during adaptation to a seasonal environment. Am. Nat. 144, 432-456 (1994).

14. Travisano, M. \& Lenski, R. E. Long-term experimental evolution in Escherichia coli. IV. Targets of selection and the specificity of adaptation. Genetics 143, 15-26 (1996).

15. Elena, S. F., Cooper, V. S. \& Lenski, R. E. Punctuated evolution caused by selection of rare beneficial mutations. Science 272, 1802-1804 (1996).

16. Modrich, P. Mechanisms and biological effects of mismatch repair. Annu. Rev. Genet. 25, 229-253 (1991).

17. Nowell, P. C. The clonal evolution of tumor cell populations. Science 194, $23-28$ (1974).

18. Moxon, E. R., Rainey, P. B., Nowak, M. A. \& Lenski, R. E. Adaptive evolution of highly mutable loci in pathogenic bacteria. Curr. Biol. 4, 24-33 (1994).

19. Lederberg, S. Genetics of host-controlled restriction and modification of deoxyribonucleic acid in Escherichia coli. J. Bacteriol. 91, 1029-1036 (1966).

20. Carlton, B. C. \& Brown, B. J. in Manual of Methods for General Bacteriology (ed. Gerhardt, P.) 222-242 (American Society for Microbiology, Washington DC, 1981).

21. Luria, S. E. \& Delbrück, M. Mutations of bacteria from virus sensitivity to virus resistance. Genetics $\mathbf{2 8}$, 491-511 (1943)

22. Miller, J. H. A Short Course in Bacterial Genetics (Cold Spring Harbor Laboratory Press, NY, 1992).

23. Pang, P. P., Lundberg, A. S. \& Walker, G. C. Identification and characterization of the $m u t L$ and $m u t S$ gene products of Salmonella typhimurium LT2. J. Bacteriol. 163, 1007-1015 (1985).

24. Taucher-Scholz, G. \& Hoffman-Berling, H. Identification of the gene for DNA helicase II of Escherichia coli. Eur. J. Biochem. 137, 573-580 (1983).

25. Bhatnagar, S. K. \& Bessman, M. J. Studies on the mutator gene, mutT, of Escherichia coli. Molecula cloning of the gene, purification of the gene product, and identification of a novel nucleoside triphosphatase. J. Biol. Chem. 263, 8953-8957 (1988).

26. Horiuchi, T., Maki, H., Maruyama, M. \& Sekiguchi, M. Identification of the dnaQ gene product and location of the structural gene for RNAse $\mathrm{H}$ of Escherichia coli by cloning of the genes. Proc. Natl Acad. Sci. USA 78, 3770-3774 (1981).

27. Schaaper, R. M. \& Cornacchio, R. An Escherichia coli dnaE mutation with suppressor activity toward mutator mutD5. J. Bacteriol. 174, 1974-1982 (1992).

28. Sambrook, E. F., Fritsch, T. \& Maniatis, J. Molecular Cloning: A Laboratory Manual 2nd edn (Cold Spring Harbor Laboratory Press, NY, 1989).

29. Ma, W. T., Sandri, G. v. H. \& Sarkar, S. Analysis of the Luria-Delbrück distribution using discrete convolution powers. J. Appl. Prob. 29, 255-267 (1992).

30. Stewart, F. M. Fluctuation tests: how reliable are the estimates of mutation rates? Genetics 137, 11391146 (1994).

Acknowledgements. We thank F. Taddei for sharing data before publicaiton; C. Zeyl for permission to cite unpublished data; A. White for help with statistical analyses; B. Bohannan, L. Ekunwe and P. Frank for technical assistance; T. Cebula, S. F. Elena, D. G. MacPhee, J. Mongold and M. Travisano for discussions; and H. Maki and J. E. LeClerc for plasmids. Supported by the US NSF and by the Center for Microbia Ecology, Michigan State University.

Correspondence and requests for materials should be addressed to P.D.S. (e-mail: paulsnie@sas.upenn. edu).

\section{Evidence from Turner's syndrome of an imprinted X-linked locus affecting cognitive function}

\section{H. Skuse ${ }^{\star}$, R. S. James $\dagger$, D. V. M. Bishop $\ddagger$, B. Coppin $₫$, P. Dalton $\dagger$, G. Aamodt-Leeper ${ }^{\star}$, M. Bacarese-Hamilton ${ }^{\star}$, C. Creswell ${ }^{\star}$, R. McGurk ${ }^{\star} \&$ P. A. Jacobs $\dagger$}

* Behavioural Sciences Unit, Institute of Child Health, 30 Guilford Street, London WC1N 1EH, UK

$\dagger$ Wessex Regional Genetics Laboratory, Salisbury District Hospital, Salisbury, Wiltshire SP2 8BJ, UK

$\ddagger$ MRC Applied Psychology Unit, 15 Chaucer Road, Cambridge CB2 2EF, UK $\$$ Wessex Regional Genetics Service, Princess Anne Hospital, Coxford Road, Southampton SO16 5YA, UK

Turner's syndrome is a sporadic disorder of human females in which all or part of one $\mathrm{X}$ chromosome is deleted ${ }^{1}$. Intelligence is usually normal ${ }^{2}$ but social adjustment problems are common ${ }^{3}$. Here we report a study of 80 females with Turner's syndrome and a single $\mathrm{X}$ chromosome, in $\mathbf{5 5}$ of which the $\mathrm{X}$ was maternally derived $\left(45, X^{m}\right)$ and in 25 it was of paternal origin $\left(45, X^{p}\right)$. Members of the $45, X^{p}$ group were significantly better adjusted, with superior verbal and higher-order executive function skills, which mediate social interactions ${ }^{4}$. Our observations suggest that there is a genetic locus for social cognition, which is imprinted ${ }^{5}$ and is not expressed from the maternally derived X chromosome. Neuropsychological and molecular investigations of eight females with partial deletions of the short arm of the $\mathrm{X}$ chromosome ${ }^{6}$ indicate that the putative imprinted locus escapes $\mathrm{X}$-inactivation ${ }^{7}$, and probably lies on $\mathrm{Xq}$ or close to the centromere on $\mathrm{Xp}$. If expressed only from the $\mathrm{X}$ chromosome of paternal origin, the existence of this locus could explain why 46,XY males (whose single $\mathrm{X}$ chromosome is maternal) are more vulnerable to developmental disorders of language and social cognition, such as autism, than are $46, \mathrm{XX}$ females ${ }^{8}$.

An increasing number of mammalian genes are known to be subject to genomic imprinting, defined as parental origin-specific differential gene expression ${ }^{5}$. No imprinted gene has yet been described on the $\mathrm{X}$ chromosome in humans ${ }^{9}$, although the Xist gene has been shown to be imprinted in the mouse ${ }^{10}$. We considered that it should be possible to identify the effects of an X-linked imprinted locus by comparing classes of females with Turner's syndrome. In this chromosomal disorder all, or a substantial part, of one $\mathrm{X}$ chromosome is missing as a result of non-disjunction (chromosome loss during gametogenesis or early cleavage of the zygote). In $70 \%$ of monosomic $(45, \mathrm{X})$ Turner-syndrome females, the single $\mathrm{X}$ chromosome is maternal in origin ${ }^{1}$; in the remainder it is paternal. Normal females $(46, \mathrm{XX})$ possess both a maternally derived $\mathrm{X}$ chromosome $\left(\mathrm{X}^{\mathrm{m}}\right)$ and a paternally derived $\mathrm{X}$ chromosome $\left(\mathrm{X}^{\mathrm{p}}\right)$, one of which is randomly inactivated in any given somatic cell ${ }^{7}$. In monosomy $\mathrm{X}$, the single chromosome is never inactivated. Differences in physical or behavioural phenotype between $45, \mathrm{X}^{\mathrm{p}}$ and $45, \mathrm{X}^{\mathrm{m}}$ Turner-syndrome subjects might therefore indicate the existence of an imprinted genetic locus.

Impaired social competence and adjustment are frequent in Turner's syndrome ${ }^{3}$, but a minority have good social skills ${ }^{11}$. Intelligence is usually normal in monosomic $(45, \mathrm{X})$ cases $^{2}$. We wished to test the hypothesis that $45, \mathrm{X}^{\mathrm{p}}$ females would be distinguishable from $45, \mathrm{X}^{\mathrm{m}}$ females by their social behaviour.

We karyotyped 80 monosomic $(45, \mathrm{X})$ females and eight with deletions of the short arm of one X chromosome (46,XXp-). The 


\section{Box 1 Scale measuring social cognition}

Complete the following section by circling 0 if the statement is not at all true of your child, 1 if it is quite or sometimes true of your child, and 2 if it is very or often true of your child:

* lacking an awareness of other people's feelings

* does not realise when others are upset or angry

* is oblivious to the effect of his/her behaviour on other members of the family

* behaviour often disrupts normal family life

* very demanding of people's time

* difficult to reason with when upset

* does not seem to understand social skills: e.g., interrupts conversation

* does not pick up on body language

* unaware of acceptable social behaviour

* unknowingly offends people with behaviour

* does not respond to commands

* has difficulty following commands unless they are carefully worded

Internal consistency for set of 12 questions: Standardised item alpha 0.94

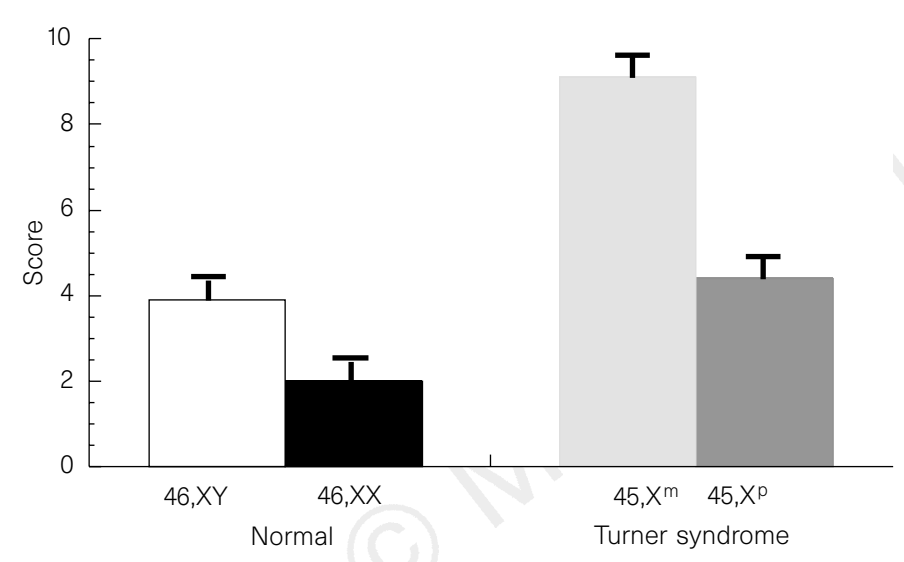

parental origin of the normal X chromosome was determined by comparing proband and parental DNA polymorphisms located on distal Xp, in a region that was deleted in both $45, \mathrm{X}$ and $46, \mathrm{XXp}-$ patients. Of the $8045, \mathrm{X}$ females, 25 were $45, \mathrm{X}^{\mathrm{p}}$ and 55 were $45, \mathrm{X}^{\mathrm{m}}$, with ages from 6 to 25 years. Clinical records did not reveal any significant group differences in terms of physical phenotype or in the provision of hormone-replacement therapy ${ }^{12}$. From a first-stage screening survey ${ }^{13}$ of parents and teachers, using standardized instruments ${ }^{14-16}$, we discovered that $40 \%$ of $45, \mathrm{X}^{\mathrm{m}}$ girls of school age had received a statement of special educational needs, indicating academic failure, compared with $16 \%$ of $45, \mathrm{X}^{\mathrm{p}}$ subjects $(P<0.05)$; the figure in the general population is just $2 \%$. We also found that clinically significant social difficulties affected $72.4 \%$ of the $45, \mathrm{X}^{\mathrm{m}}$ subjects over 11 years of age (21 of 29 ), compared with $28.6 \%$ of 45, $\mathrm{X}^{\mathrm{p}}$ females $(4$ of 14$)(P<0.02)$.

Such phenotypic variability between the two classes of monosomy X subjects could indicate the existence of an imprinted genetic locus, at which gene(s) that influence social adjustment are expressed only from the paternally derived X chromosome. On the maternally derived $\mathrm{X}$ chromosome, the corresponding locus would be silenced. This could account for the excess of social and learning difficulties among $45, \mathrm{X}^{\mathrm{m}}$ females compared with the $45, \mathrm{X}^{\mathrm{p}}$ variant. Pilot interviews and observations showed that $45, \mathrm{X}^{\mathrm{m}}$ females in particular lacked flexibility and responsiveness in social interactions. We therefore devised a questionnaire relevant to social cognition to summarize the main features of their behaviour (Box 1). Parents of our sample of Turner's syndrome females and the parents of age-matched normal male and female comparisons

\section{Table 1 Neuropsychological test results}

\begin{tabular}{|c|c|c|c|c|}
\hline & \multicolumn{2}{|c|}{ Turner's syndrome } & \multicolumn{2}{|c|}{ Normal } \\
\hline & $45, X^{m}$ & $45, X^{p}$ & $46, X X$ & $46, X Y$ \\
\hline & mean \pm s.d.) & (mean \pm & (mean \pm s.d.) & nean \pm s.d.) \\
\hline \multicolumn{5}{|l|}{ IQ } \\
\hline Verbal & & & $.1 \pm 16.7$ & $98.6 \pm 17.1$ \\
\hline Non-verbal & $79.5 \pm 18.8$ & & - & \\
\hline \multicolumn{5}{|l|}{ Executive function tasks } \\
\hline Behavioural inhibition & 8.7 & & $5.3 \pm 4.1$ & $6.8 \pm 3.4$ \\
\hline Planning ability & $6.1 \pm 1.7$ & & $6.6 \pm 1.6$ & $7.2 \pm 1.4$ \\
\hline \multicolumn{5}{|c|}{$\begin{array}{l}\text { The } 45, X^{p} \text { females have significantly higher verbal IQ than } 45, X^{m} \text { subjects }(P<0.02) \text {, but } \\
\text { neither Turner group differs significantly from the normal female comparisons. Non-verbal } \\
\text { IQ was measured only in Turner-syndrome subjects and does not significantly distinguish } \\
\text { the subgroups; it incorporates tests of visuospatial abilities, which are known to be } \\
\text { specifically impaired in this condition }{ }^{2,29} \text {. In all analyses using the executive function } \\
\text { measures, age has been covaried because, unlike conventional IQ measures, these tests } \\
\text { are not yet standardized for age. Behavioural inhibition scores (Same-Opposite World) are } \\
\text { measured in seconds, higher scores indicating more difficulty completing the task accu- } \\
\text { rately. The } 45, X^{m} \text { females are less competent than either } 45, X^{p} \text { subjects }(P<0.02) \text { or normal } \\
\text { females }(P<0.03) \text {. Males are less competent than normal females }(P<0.03) \text {. On the } \\
\text { planning task (Tower of Hanoi), neither the two Turner subgroups nor normal males and } \\
\text { females are significantly distinguished from one another by the mean highest level } \\
\text { achieved. }\end{array}$} \\
\hline
\end{tabular}

Figure 1 Subscale scores (mean + s.e.) of questionnaire on social-cognitive impairment (Box 1). Higher scores indicate poorer social cognitive skills. The $45, X^{m}$ Turner-syndrome females score higher than $45, X^{p}$ females and both normal groups $(P<0.0001)$. Normal males score higher than normal females $(P<0.001)$; the effect size of this difference is 0.58 , implying that the upper $50 \%$ of females score higher than approximately $72 \%$ of males. The ratios of mean socialdysfunction scores male: female and $45, X^{m}: 45, X^{p}$ are very similar $2.2: 1$ and $2.1: 1$, respectively). The overall higher scores for the Turner-syndrome subjects, compared with normal females, may reflect the contribution made by visuospatial abilities to social cognition"1. These abilities are impaired equally in both monosomic groups. No information regarding parental origin of the normal $\mathrm{X}$ chromosome was made available to parents, their consultants, or members of the research team gathering these or other data.

completed the questionnaire. The results for subjects aged from 6 to 18 years of age confirm there are significant differences between $45, \mathrm{X}^{\mathrm{m}}$ and $45, \mathrm{X}^{\mathrm{p}}$ females in the predicted direction (Fig. 1). We found that $45, \mathrm{X}^{\mathrm{m}}$ subjects obtained significantly higher scores than $45, \mathrm{X}^{\mathrm{p}}$ females on our measure of social-cognitive dysfunction. Normal boys also obtained significantly higher scores on the questionnaire than did normal girls, indicating poorer social cognition (Fig. 1). The magnitude and direction of this difference are compatible with the hypothesis that there is an imprinted locus on the X chromosome that influences the development of social cognitive skills (although the finding is of course also compatible with other explanations of gender differences in behaviour ${ }^{17}$ ). If the putative locus only expressed a gene (or genes) from the $\mathrm{X}$ chromosome of paternal origin $\left(\mathrm{X}^{\mathrm{p}}\right)$, we would expect a tendency for normal females to have superior social cognitive skills than males. Because males $(46, \mathrm{XY})$ invariably inherit their single $\mathrm{X}$ chromosome from their mothers, the genetic locus would be silenced. In contrast, the gene(s) would be expressed from $\mathrm{X}^{\mathrm{p}}$ in approximately half of the cells of normal females if it were inactivated, and from all cells if it escaped X-inactivation ${ }^{7}$.

We hypothesized that an imprinted X-linked locus, either without a Y-linked homologue or with a Y homologue showing a lower level of expression, could also explain why males are markedly more vulnerable than females to pervasive developmental disorders affecting social adjustment and language, such as autism ${ }^{8}$. Accordingly, 45, $\mathrm{X}^{\mathrm{m}}$ Turner females should be exceptionally vulnerable to disorders of language and social adjustment that are usually more common in males. Consistent with this hypothesis, we identified 


\begin{tabular}{|c|c|c|c|}
\hline \multirow[t]{2}{*}{ Patient } & \multirow[t]{2}{*}{ Karyotype } & \multicolumn{2}{|c|}{ Breakpoints between } \\
\hline & & proximal & distal \\
\hline $85 / 5142$ & $46, X, \operatorname{del}(X)(q t e r \rightarrow p 22:)$ & DXS8036 & DXS1053 \\
\hline $95 / 4894$ & $46, X, \operatorname{del}(X)($ qter $\rightarrow$ p21.2:) & DXS1036 & DXS985 \\
\hline $95 / 4247$ & $45, X[33] / 46, X, \operatorname{del}(X)($ qter $\rightarrow$ p21.2: $)[17]$ & DXS1036 & DXS985 \\
\hline $95 / 3557$ & $45, X[32] / 46, \operatorname{del}(X)($ qter $\rightarrow$ p22.11: $[68]$ & DXS8039 & DXS8049 \\
\hline $91 / 219$ & $46, X, \operatorname{del}(X)($ qter $\rightarrow$ p11:) & DXS1208 & DXS1055 \\
\hline $96 / 863$ & $46, X, \operatorname{del}(X)($ qter $\rightarrow$ 11.2:) & DXS8062 & DXS1003 \\
\hline $96 / 8266$ & $46, X, \operatorname{del}(X)($ qter $\rightarrow$ p11.23:) & DXS423E & UBE1 \\
\hline $96 / 5509$ & 45,X[9]/46,X,der $(X) \operatorname{del}(X)($ p21.2 $\rightarrow$ pter $) \operatorname{inv}(X)(p 21.2$ q22.1)[166] & DXS1067 & DXS8039 \\
\hline
\end{tabular}

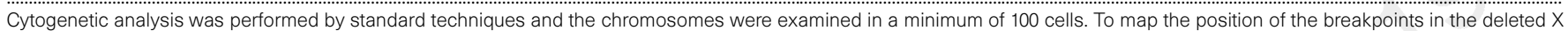

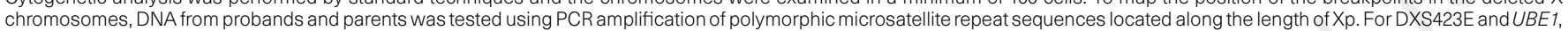

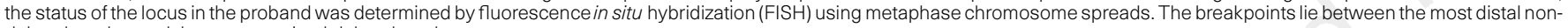
deleted marker and the most proximal deleted marker.

three Turner-syndrome females with autism (meeting ICD-10 criteria $)^{18}$, out of the total unbiased sample assessed personally in the course of this investigation (3.75\%). All three females had retained a normal maternal $\mathrm{X}$ chromosome. The population prevalence of autism is less than 1 per 10,000 females $^{8}$.

We then sought corresponding differences in the results of neuropsychological testing of both normal and Turner-syndrome subjects. We found that $45, \mathrm{X}^{\mathrm{p}}$ females were significantly superior in verbal intelligence to $45, \mathrm{X}^{\mathrm{m}}$ females (Table 1 ). Verbal IQ was negatively correlated with the social dysfunction score in the sample as a whole $(r=-0.41, P<0.002)$. Both monosomic Turner subgroups were equivalently impaired in non-verbal (including visuospatial) abilities.

We subsequently performed several more focused neuropsychological assessments. First, although we had found that verbal abilities were moderately good predictors of social cognition, we hypothesized that higher-order cognitive skills would be better predictors. These are not measured directly by conventional intelligence tests. The executive functions of the prefrontal cortex ${ }^{4}$ exert an important influence on social interactions, and include skills that allow for the development of strategies of action and the inhibition of distracting impulses when striving towards a goal. Developmental disorders of social adjustment and language are associated with impairment in measures of executive function ${ }^{19}$. Many monosomic Turner-syndrome subjects have executive-function deficits ${ }^{2}$. We also predicted that $45, \mathrm{X}^{\mathrm{p}}$ females would perform better than $45, \mathrm{X}^{\mathrm{m}}$ females in tests of executive function skills. Finally, we predicted that abilities in which $45, \mathrm{X}^{\mathrm{p}}$ subjects were superior to $45, \mathrm{X}^{\mathrm{m}}$ subjects would also distinguish normal females from males, and in the same direction.

We chose tests of both planning ability (Tower of Hanoi) and behavioural inhibition (Same/Opposite World). The results were consistent with the initial hypothesis. Although the social-cognitive impairment score correlated independently with verbal IQ and with both measures of executive function, only planning ability $(r=-0.4 ; P<0.006)$ and behavioural inhibition $(r=-0.37$; $P<0.015)$ retained significance when the three variables were forced into a multiple regression analysis. The second prediction was partly confirmed: there were significant differences between $45, \mathrm{X}^{\mathrm{p}}$ and $45, \mathrm{X}^{\mathrm{m}}$ subjects in terms of the behavioural inhibition task, although not on the test of planning ability. The third prediction was fully confirmed (Table 1): there was no significant difference in the highest level achieved on the planning task between normal males and females. However, on the behavioural-inhibition task, normal females were superior to males and their mean scores were very similar to those of the $45, \mathrm{X}^{\mathrm{p}}$ subjects. Previous reports have noted gender differences on inhibition tasks, and they have been conceptually linked to corresponding differences in social behaviour ${ }^{20}$.

We then attempted to map the putative imprinted locus, provisionally, by studying eight females, ascertained as part of the Turnersyndrome project, who had large terminal deletions of the short arm of the paternally derived $\mathrm{X}$ chromosome (a $46, \mathrm{X}^{\mathrm{m}} \mathrm{X}^{\mathrm{p}} \mathrm{p}$-karyotype). These deletions all extended to a point proximal to the MLS gene at Xp22.3 (Table 2); the paternal X chromosome was consequently preferentially inactivated ${ }^{6}$. On examination, no-one in this series was found to have any significant learning difficulties. The mean verbal intelligence score for the group was 103.4 (s.d., 13.7), and their mean non-verbal IQ was 93 (s.d., 11.2). Their mean social dysfunction score was 3.75 (s.d., 3.1), a value very similar to that of the $45, \mathrm{X}^{\mathrm{p}}$ subjects (Fig. 1). We drew the following conclusions from these data. First, the imprinted locus had not been deleted on the structurally abnormal paternal X chromosome, and so it must lie on $\mathrm{Xq}$ or on $\mathrm{Xp}$ closer to the centromere than, UBE1 at Xp11.23. Second, the imprinted locus was not subject to $\mathrm{X}$-inactivation, or the preferentially inactivated, partly deleted chromosome would not have expressed it. We already know of several genes that escape $\mathrm{X}$-inactivation ${ }^{21}$.

We expected that isochromosomes of the long arm of the $\mathrm{X}$ chromosome $[\mathrm{i}(\mathrm{Xq})]$ would help in the mapping of the putative imprinted locus. However, virtually all $\mathrm{i}(\mathrm{Xq})$ chromosomes have been shown to contain proximal Xp sequences ${ }^{22}$. Duplication and consequent trisomy of the long arm of the $\mathrm{X}$ chromosome further complicate the interpretation of correlations between phenotype and genotype. Accordingly, this approach did not provide unambiguous evidence to assist in the deletion mapping of the locus.

An imprinted locus is not the only possible explanation for our findings. Among the $45, \mathrm{X}^{\mathrm{p}}$ females, there may have been a greater degree of cryptic mosaicism (with a normal 46,XX cell line) than among those who were $45, \mathrm{X}^{\mathrm{m}}$. Some degree of mosaicism in apparently monosomic females may be essential for the fetus to avoid spontaneous abortion ${ }^{23}$. We examined both blood and cheek cells, tissues of mesodermal and ectodermal origin, respectively, and found two cryptic mosaics, but both were from the $45, \mathrm{X}^{\mathrm{m}}$ group.

Males are substantially more vulnerable to a variety of developmental disorders of speech, language impairment and reading disability, as well as more severe conditions such as autism ${ }^{8}$. Our findings are consistent with the hypothesis that the locus described, which we propose to be silent both in males and $45, \mathrm{X}^{\mathrm{m}}$ females, acts synergistically with susceptibility loci elsewhere on the genome to increase the male-to-female prevalence ratio of such disorders. Our data on normally developing children suggest it may also exert an effect on social and cognitive abilities in the normal range. These preliminary findings could thus provide evidence for the evolution of an imprinted X-linked locus that underlies the development of sexual dimorphism in social behaviour ${ }^{17}$.

\section{Method}

Subjects. This study, which was approved by the local hospital ethics committee, involved 88 females with Turner's syndrome ( 80 monosomic and 8 partial X-chromosome deletions; age range, 6-25 years). They were selected from a national survey of Turner's syndrome and from records of the Wessex Regional Laboratory. The mean age of the $45, \mathrm{X}^{\mathrm{m}}$ females was 162.3 months (s.d., 57.6), that of the $45, \mathrm{X}^{\mathrm{p}}$ females was 164.5 months (s.d., 57.7), and that of 
the Xp-females was 185.8 months (s.d., 74.9). All subjects were healthy, with no significant neurological disease. Females with an Xp-chromosome were all referred for investigation because of short stature in middle childhood, with one exception who was karyotyped at birth. Neuropsychological test results are presented for subjects with verbal IQs $\geqslant 65$ (three $45, X^{m}$ subjects and one $45, X^{p}$ subject had verbal IQs that fell out of range). Parents rated 70 normal males and 71 normal females (age range, 6-18 years) on the social-cognition scale. The neuropsychological test battery was used to assess 68 normal males and 91 normal females (age range, 6-25 years). Verbal IQs were in the range 65-151. All normal comparison subjects were recruited from urban and suburban schools (6-18 years) and from hospital staff (18-25 years).

Behavioural and cognitive measures. Initial screening was conducted by postal questionnaires using a well-standardized set of instruments ${ }^{14-16}$. These were completed by parents, teachers and the Turner-syndrome subjects themselves (11 years and over). The social cognition questionnaire (Box 1) was completed by parents only. In a survey of 175 Turner-syndrome subjects for whom we obtained parental ratings on two occasions, a mean of 2.7 years apart, the intraclass correlation coefficient was $0.81(P<0.01)$. Scores correlate with the self-rated social problem subscale of the $\mathrm{YSR}^{16} 0.58(P<0.002)$, with the teacher rating on the $\mathrm{TRF}^{15} 0.54(P<0.001)$, and with the parent-rated $\mathrm{CBCL}^{14}$ $0.69(P<0.001)$. The range of scores was $0-23$ in the Turner-syndrome sample and $0-21$ in the normal sample (maximum score of 24 ). The $\mathrm{CBCL}^{14}$ was completed by 70 parents, the YSR ${ }^{16}$ was completed by 40 subjects over 11 years of age, and the TRF ${ }^{15}$ was completed by 45 teachers. Clinical significance of social problems was estimated according to clinical $T$ scores $^{14-16}$. Measures of cognition included the Wechsler Intelligence Scales for Children (WISC III$\mathrm{UK})^{24}$ and the Wechsler Adult Intelligence Scales-Revised (WAIS-R) ${ }^{25}$. The behavioural inhibition task was the Same-Opposite World subtest from the Test of Everyday Attention for Children ${ }^{26}$. This yields a time measure that ascertains the difference in latency for a subject responding to a series of stimuli on a task of sequential responses, which are named both as they appear and then opposite to their appearance. The subject reads a random series of numbers ( 1 and 2) saying 'one' to 1 , and 'two' to 2 . The subjects then repeat the task on a new series, but this time they have to inhibit the prepotent response and instead say 'two' to 1 , and 'one' to 2 , correcting any errors before proceeding. Testretest reliability on a sample of 70 normal children gave an intraclass correlation coefficient of $0.62(P<0.001)$. The Tower of Hanoi task was based on the procedure described previously $y^{27}$. It was scored according to the most complex level of the problem the child could solve reliably. Test-retest reliability gave an intraclass correlation coefficient for the highest level achieved of 0.45 $(P<0.001)$, which is in line with expectations for a test that makes novel demands of this nature ${ }^{28}$.

Received 17 February; accepted 1 May 1997

1. Jacobs, P. A. et al. A cytogenetic and molecular reappraisal of a series of patients with Turner's syndrome. Ann. Hum. Genet. 54, 209-223 (1990).

2. Pennington, B. F. et al. The neuropsychological phenotype in Turner syndrome. Cortex 21, 391-404 (1985).

. McCauley, E., Ito, J. \& Kay, T. Psychosocial functioning in girls with the Turner syndrome and short stature. J. Am. Acad. Child Psychiat. 25, 105-112 (1986).

4. Damasio, A. R. On some functions of the human prefrontal cortex. Proc. N. Y. Acad. Sci. 769, 241-251 (1995).

5. Barlow, D. P. Gametic imprinting in mammals. Science 270, 1610-1613 (1995)

6. Ballabio, A. \& Andria, G. Deletions and translocations involving the distal short arm of the human X chromosome: review and hypotheses. Hum. Mol. Genet. 1, 221-227 (1995).

7. Lyon, M. F. Gene action in the X-chromosome of the mouse (Mus musculus L). Nature 190, 372-373 (1961).

8. Bailey, A., Philips, W. \& Rutter, M. Autism: towards an integration of clinical, genetic, neuropsychological and neurobiological perspectives. J. Child Psychol. Psychiat. 37, 89-126 (1996).

9. Ledbetter, D. H. \& Engel, E. Uniparental disomy in humans: development of an imprinting map and its implications for prenatal diagnosis. Hum. Mol. Genet. 4, 1757-1764 (1995).

10. Zuccotti, M. \& Monk, M. Methylation of the mouse Xist gene in sperm and eggs correlates with imprinted Xist expression and paternal X-inactivation. Nature Genet. 9, 316-320 (1995).

11. McCauley, E., Kay, T., Ito, J. \& Trader, R. The Turner syndrome: cognitive deficits, affective discrimination and behaviour problems. Child Dev. 58, 464-473 (1987).

12. Saenger, P. Clinical Review 48: The current status of diagnosis and therapeutic intervention in Turner's syndrome. J. Clin. Endocrinol. Metabol. 77, 297-301 (1993).

13. Skuse, D., Percy, E. L. \& Stevenson, J. in Growth, Stature, and Adaptation. Behavioral, Social, and Cognitive Aspects of Growth Delay (eds Stabler, B. \& Underwood, L.) 151-164 (UCP, Chapel Hill, 1994).

14. Achenbach, T. M. Manual for the Child Behavior Checklist/4-18 and 1991 Profile (Department of Psychiatry, University of Vermont, Burlington, VT, 1991).

15. Achenbach, T. M. Manual for the Teacher's Report Form and 1991 Profile (Department of Psychiatry, University of Vermont, Burlington, VT, 1991).

16. Achenbach, T. M. Manual for the Youth Self-Report Form and 1991 Profile (Department of Psychiatry, University of Vermont, Burlington, VT, 1991)
7. Eagley, A. H. The science and politics of comparing men and women. Am. Psychol. 50, 145-158 (1995)

18. World Health Organization The ICD-10 Classification of Mental and Behavioural Disorders: Clinical Descriptions and Diagnostic Guidelines (World Health Organizaiton, Geneva, 1992).

19. Pennington, B. F. \& Ozonoff, S. Executive functions and developmental psychopathology. J. Child Psychol. Psychiat. 37, 51-87 (1996).

20. Bjorklund, D. F. \& Kipp, K. Parental investment theory and gender differences in the evolution of inhibition mechanisms. Psychol. Bull. 120, 163-188 (1996).

21. Disteche, C. M. Escape from X inactivation in human and mouse. Trends Genet. 11, 17-22 (1995).

22. Wolff, D. J., Miller, A. P., Van Dyke, D. L., Schwartz, S. \& Willard, H. F. Molecular definition of breakpoints associated with human $\mathrm{Xq}$ isochromosomes: implications for mechanism of formation. Am. J. Hum. Genet. 58, 154-160 (1996).

23. Hassold, T., Pettay, D., Robinson, A. \& Uchida, I. Molecular studies of parental origin and mosaicism in 45,X conceptuses. Hum. Genet. 89, 647-652 (1992).

24. Wechsler, D. Wechsler Intelligence Scale for Children 3rd UK edn (Psychological Corporation, London, 1992).

25. Wechsler, D. Wechsler Adult Intelligence Scales-Revised (Psychological Corporation, New York, 1986),

26. Borys, S. V., Spitz, H. H. \& Dorans, B. A. Tower of Hanoi performance of retarded young adults and nonretarded children as a function of solution length and goal state. J. Exp. Child Psychol. 33, 87-110 (1982).

27. Manly, T., Robertson, I. H. \& Anderson, V. The Test of Everyday Attention for Children (TEACh) (Thames Valley Test Company, Bury St Edmunds, in the press).

28. Rabbitt, P. M. A. in Methodologies of Frontal and Executive Function (ed. Rabbitt, P. M. A.) (Psychology Press, Hove, in the press).

29. Temple, C. M. \& Carney, R. A. Patterns of spatial functioning in Turner's syndrome. Cortex 31, 109118 (1995).

Acknowledgements. We thank E. Percy, S. Cave, A. O'Herlihy, R. South, J. Smith, M. Power and D. Robinson for assistance; M. Pembrey for comments and discussion; many. assisting with the recruitment of patients, the schools who participated, and all of the subjects of our assisting with the recruitment of patients, the schools who participated, and all of the subjects of our
investigation and their families for their time. This research was supported by the Wellcome Trust and the Child Growth Foundation. Compilation of the national register of Turner syndrome was supported by the British Society for Paediatric Endocrinology and by Pharmacia.

Correpsondence and requests for material should be addressed to D.H.S. (e-mail: dskuse@ich.ucl.ac.uk).

\section{Molecular evidence for an ancient duplication of the entire yeast genome}

\section{Kenneth H. Wolfe \& Denis C. Shields}

Department of Genetics, University of Dublin, Trinity College, Dublin 2, Ireland

Gene duplication is an important source of evolutionary novelty $^{1,2}$. Most duplications are of just a single gene, but Ohno ${ }^{1}$ proposed that whole-genome duplication (polyploidy) is an important evolutionary mechanism. Many duplicate genes have been found in Saccharomyces cerevisiae, and these often seem to be phenotypically redundant ${ }^{3-7}$. Here we show that the arrangement of duplicated genes in the $S$. cerevisiae genome is consistent with Ohno's hypothesis. We propose a model in which this species is a degenerate tetraploid resulting from a whole-genome duplication that occurred after the divergence of Saccharomyces from Kluyveromyces. Only a small fraction of the genes were subsequently retained in duplicate (most were deleted), and gene order was rearranged by many reciprocal translocations between chromosomes. Protein pairs derived from this duplication event make up $13 \%$ of all yeast proteins, and include pairs of transcription factors, protein kinases, myosins, cyclins and pheromones. Tetraploidy may have facilitated the evolution of anaerobic fermentation in Saccharomyces.

We searched systematically for duplicated regions ${ }^{6,7}$ in the complete yeast genome ${ }^{8}$ by using BLASTP ${ }^{9}$ amino-acid sequence similarity searches of all yeast proteins against one another, and plotted the results on dot matrices. Duplicate regions are visible as a diagonal series of 'hits' with conserved gene orientation. In the example shown in Fig. 1, three separate diagonals indicate three distinct regional duplications between chromosomes X and XI. Within each region the homologues are interspersed with genes that are not now duplicated. We propose that this is the result of random deletion of individual duplicated genes from one or other chromosome subsequent to the initial duplication of the whole region.

In the whole genome, 55 duplicate regions were identified 